\title{
Batch-Level Costs In Activity-Based Costing Refinement, Optimization \& Allocation
}

M.A. Sangeladji, California State University, Northridge, USA J. Damooei, California Lutheran University, USA

\begin{abstract}
In the past decade, the Activity-Based Costing and the allocation of the batch-level costs have been presented and discussed in almost all cost/managerial accounting textbooks. A widely used example of batch-level cost, in most of the textbooks, is the set-up cost. In almost all of these textbooks, the annual set-up cost is assumed to be known in advance and is allocated based on the number of set-ups. In reality, the set-up cost should be determined first before it can be allocated properly. For the computation of the optimal total set-up cost, first the various factors influencing this category of cost should be discussed and then the methods of the allocation be applied. This paper discusses the various factors affecting the calculation of annual set-up cost. It also demonstrates a model that computes the optimum size of each set-up and the economical number of annual set-ups. Based on the outcomes of the model, the paper demonstrates the calculation of total allocable set-up cost and its allocation to various products.
\end{abstract}

\section{INTRODUCTION}

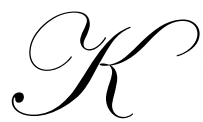

nowing different costs and their behaviors are prerequisite for making correct and effective managerial decisions. Traditional accounting classifies costs into product cost and period cost and subgroups the period cost to marketing, administration, and general expenses based on their functional aspects. It also recognizes two major behaviors for these costs: variable and fixed. The mixed costs, which are usually the combination of variable and fixed, are generally separated to fixed and variable costs by the application of tools, such as high-low method or regression models.

Contemporary accounting, which began by the introduction of Activity-Based Costing in the late 1980s, ${ }^{1}$ on the other hand, classifies costs based on activity. ${ }^{2}$ It recognizes four different types of activities: unit-level, batchlevel, product-level, and facility-level activities. As in the traditional accounting, the costs of these four types of activities can be classified as fixed or variable. The costs of unit-level and product-level are purely variable. The cost of facility-level is usually fixed. The cost of batch-related activities is generally fixed per batch regardless of the number of units in each batch, but the total of the batch-related cost per year varies with the number of batches processed.

Despite the similarity of thought in traditional and contemporary accounting in regard to the cost behavior, the classification of costs on the activity basis has been considered more effective for cost allocation, unit cost determination, and making managerial decisions. In Activity-Based Costing, rather than arbitrary allocation of costs to different products, attempts are made to locate proper cost drivers and allocate costs accordingly. ${ }^{3}$ The logical cost driver for the allocation of unit-level activity costs is unit of production or constituents of each unit, such as direct labor hours, direct labor cost, or machine hours. Since the product-level activity cost is direct and traceable to one product or a group of products, the cost driver for the allocation of this category is product. The facility-level activity costs are generally fixed in nature, and finding effective cost drivers for their allocation is hard. The only category of cost that needs particular attention is the batch-level activity costs. The driver for this category is the 
number of batches. Thus, the total cost of this category should be allocated based on the number of batches used for each product.

\section{COMMON EXAMPLES OF BATCH-LEVEL COSTS}

In the past decade, the Activity-Based Costing and the allocation of the batch-level costs have been presented and discussed in almost all cost/managerial accounting textbooks. A widely used example of batch-level costs, in most of the textbooks, is the set-up cost. According to one of the textbooks, "An example of a batch-level cost is the cost of setting up a machine". ${ }^{4}$ According to another book, "Batch-level activities consist of tasks that are performed each time a batch is performed, such as processing purchase orders, setting up equipment, packing shipments to customers, and handling material. Costs at the batch level depend on the number of batches processed rather than on the number of units produced." Furthermore, most of the numerical examples of the batch-level costs presented in these books involve the set-up cost.

\section{ISSUES REGARDING THE DETERMINATION OF TOTAL SET-UP COST}

In almost all cost and managerial textbooks, the annual set-up cost is assumed to be known in advance and is allocated based on the number of set-ups. In reality, this category of cost should be determined first before it can be allocated properly.

Computationally, the total annual set-up cost can be determined by the multiplication of (a) the number of set-ups and (b) the cost of each set-up, if they are known in advance. The determination of cost of each set-up, which generally remains the same regardless of the size of the set-up (number of units produced in each set-up), is not a difficult task. However, the determination of total annual set-up cost is involved because of the interaction of the number of annual set-ups with the size of each set-up.

The number of annual set-ups can be determined arbitrarily. However, this approach may not be a wise nor an economical one. In order to determine a proper and economical number of annual set-ups, one needs to consider the variables affecting its calculation. The variables include (a) total annual demand for a product, (b) number of units produced in each set-up (size of the set-up), (c) total annual cost for carrying units produced in each set-up and finally (d) total annual set-up cost.

The number of set-ups has both favorable and unfavorable effects on the amount of total annual set-up cost and total annual carrying cost. It also has a direct relationship with the number of units produced in each setup, assuming a predetermined annual demand. A larger size for each set-up reduces the number of annual set-ups. A lesser number of annual set-ups means a smaller size of total annual set-up cost but a bigger size of production in each set-up, which in turn increases the total annual carrying cost.

Thus, the size of each set-up should be determined first with the objective of minimizing the total annual set-up and carrying cost. After determining the economic size of each set-up and calculating the optimum total annual set-up cost, then the set-up cost can be allocated based on the number of set-up as suggested by ActivityBased Costing. This, indeed, can be accomplished easily by the application of a traditional inventory model called "Economic Order Quantity" or "EOQ".

The EOQ model had been used heavily in the past for managing the purchase of raw material and minimizing the annual inventory costs. The usefulness and application of the EOQ model has diminished significantly in the past decade after the Just-In-Time concept earned more popularity. This is mostly justifiable since the advent of the internet and advancement in technology have reduced notably the magnitude of ordering cost for purchasing raw materials and supplies. It should be noted that the term of ordering cost for purchasing raw material is equivalent to the set-up cost in our discussion. Both are batch-related costs. However, in contrast to the decline in the ordering cost for purchasing raw material and supplies, the set-up cost for manufacturing parts or products is still significant for some manufacturing companies. For this reason, the application of the EOQ model (or Economic Set-up Quantity: ESQ, as it is called in this paper) is still beneficial and useful for the following purposes: 
a) The determination of the size of each set-up and the calculation of the total number of annual set-ups

b) The computation and optimization of the annual total set-up cost

c) The allocation of annual total set-up cost to products as suggested by Activity-Based Costing.

\section{A REVIEW OF THE MODEL}

The main objective of the ESQ model is to minimize the annual costs that are affected by the size and the number of set-ups. Two categories of cost, which are affected by these factors, are the Annual Total Set-up Cost and the Annual Total Carrying Cost. The number of annual set-ups affects the former, while the latter is sensitive to the size of each set-up. Because of this interrelationship, the total annual set-up cost cannot be determined economically and cannot be allocated properly on the basis of number of set-ups if the proper size of each order is not known in advance.

The main objective of the ESQ is to determine the economical size of each set-up that minimizes the total annual set-up and carrying cost. After the size of each set-up is determined, the number of annual set-ups, as well as the cost of total annual set-up, can be calculate and allocated based on the total number of set-ups, as suggested by the Activity-Based Costing model.

The economic size of each set-up is determined where the total annual set-up and carrying costs are equal to each other as demonstrated below:

\begin{tabular}{|c|c|}
\hline Total Annual Set-up Cost = & $\begin{array}{c}\text { D } \\
\text { ESQ }\end{array}$ \\
\hline Total Annual Carrying Cost = & $\begin{array}{c}\text { ESQ } \\
=-----X \text { \$CC } \\
2\end{array}$ \\
\hline
\end{tabular}

Where: $\quad \mathrm{D}=$ Annual Demand for a product

ESQ = Economic Set-up Quantity (Economic Size of each set-up)

$\$$ SUC $=$ Set-up cost for each time a set-up is performed

$\$ C C=$ Cost of Carrying One unit of product for One year

$\mathrm{ESQ}=\sqrt{\frac{2 \times \mathrm{D} \times \$ S U C}{\$ C C}}$

\section{APPLICATION OF ESQ MODEL FOR COST REDUCTION IN THE CONTEXT OF ACTIVITY-BASED COSTING}

Let us use the example presented in one of the textbooks. ${ }^{6}$

"Assume that machine set-up to cast product parts costs $\$ 900$. Two different parts are to be manufactured during day; Therefore, two set-ups will be needed at a total cost of $\$ 1,800$. After the first set-up, production will generate 3,000 Type A parts; the machine will then be reset to generate 600 Type B parts. These specific numbers of parts are needed for production because the company is on a just-in-time system" ....

"Because the cost is actually created by a batch-level driver, the following cost assignments are more appropriate:

Type A parts: $\$ 900$ divided by 3,000 units $=\$ 0.30$ per unit

Type B parts : $\$ 900$ divided by 600 units $=\$ 1.50$ per unit ${ }^{\$ 7}$ 
* Bolding is added by the authors of the paper.

The first question about the above example is whether the just-in-time system is an economical decision for this company. The second question is whether the two daily set-ups and production of 3,000 and 600 units respectively for part $A$ and $B$ in each set-up is a good production policy. Without answering these questions, the allocation of the set-up cost based on the series of assumptions may not be complete and useful as suggested by the Activity-Based Costing.

To answer the above questions, the size of annual demand for each product and the cost of carrying one unit of each product in the inventory for one year should be know in advance. For calculating the annual demand, we need to know the number of days this company operates during a year. Let us assume that the number of annual working days is 300 . Let us also assume that the cost of carrying one unit of each product in inventory for one year is $\$ 2$. Based on these and other assumptions made in the problem, the following data are available:

Annual Demand $=$ (number of daily production) $\mathrm{X}$ (number of working days per year)

Annual Demand for part A $=3,000$ units X $300=900,000$

Annual Demand for part B $=600$ units X $300=180,000$

$\$ S U C=\$ 900$

$\$ C C=\$ 2$

By applying the ESQ model to the above data, one can determine that Just-in-time policy is not economical for the company as presented below:

\section{Cost of Alternative 1 (Just-in-time policy) for part A:}

Total annual set-up cost $=$ (one set-up per day) $X(300$ days per year $) X(\$ 900$ cost per each set-up $)=\$ 270,000$

Total annual carrying cost $=\$ 0$ Because all units are used in the same day of production)

Total of set-up cost and carrying cost for part $A=\$ 270,000+\$ 0=\$ \mathbf{2 7 0 , 0 0 0}$.

\section{Cost of Alternative 2 (ESQ policy) for part A:}

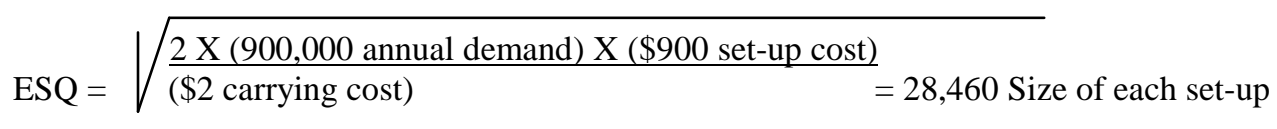

Annual demand $(900,000)$

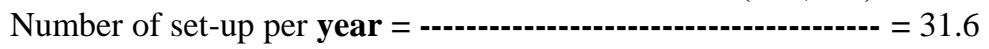

Size of each set-up, ESQ $(28,460)$

Total annual set-up cost $=31.6 \quad \mathrm{X} \$ 900=\$ 28,440$

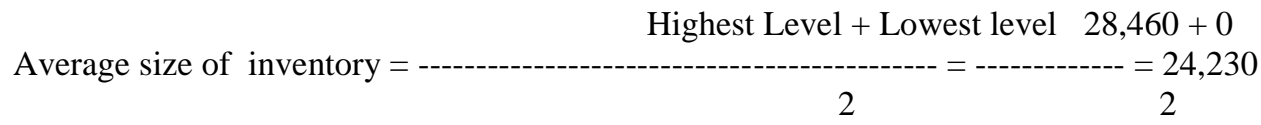

Total annual carrying cost $=24,230 \times \$ 2=\$ 28,440$

Total of set-up cost and carrying cost for part $\mathrm{A}=\$ 28,440+\$ 28,440=\mathbf{\$ \mathbf { 5 6 } , \mathbf { 8 8 0 }}$

Conclusion: The Just-in-time policy is not economical because the total cost of Alternative 1 far exceeds the cost of alternative $2,(\$ 270,000$ vs. $\$ 56,880)$.

A similar conclusion can be reached for part B. 
The answer to the second question delineated above is negative as well. As was calculated above, the size of each set-up for part A should be 28,440 units (see ESQ) instead of 3,000 units suggested in the original example. The production of 28,440 units A in each set-up requires only 31.6 (or 32 ) set-ups per year rather the one set-up per day.

\section{APPLICATION OF ESQ MODEL FOR SET-UP COST DETERMINATION \& ALLOCATION}

Before further discussion of cost allocation, it is important to understand the type of set-up and carrying costs that influence the computation of ESQ and the size and the number of set-ups.

Constant Set-up Costs: There are some set-up costs for which the annual total amount would not change with the change in the number of annual set-ups or the size of each set-up. Good examples of these costs are the depreciation cost (expense) for tools and equipment used in each set-up and the salary of crews performing the set-up. These costs could be termed as "facility-level costs" and should not be included in \$SUC for the calculation of ESQ. However, they should be added to the allocable set-up cost (explained below) and be allocated to different products based on the number of set-ups.

Batch-Level Set-up Costs: There are set-up costs that vary with the number and size of set-ups, and consequently their total annual amount changes in direct proportion to the number of annual set-ups. Good examples are raw material and labor costs needed for performing each set-up. These costs should be determined for each set-up and included in \$SUC for the calculation of ESQ. The total of these costs per year also should be added to the allocable set-up cost for allocation to each product based on the number of set-ups.

Unit-Level Carrying Costs: The carrying cost or holding cost is those costs that companies incur because of holding units in inventory. According to the zero inventory policy and Just-in-Time concept, these costs are "Not-ValueAdded" and should be eliminated or minimized. The entire elimination of unit-level carrying cost by increasing the frequency of set-ups and reducing the size of each set-up may not be economical if it triggers a higher total of annual set-up and carrying costs (as in the example discussed before).

A prime and ever-existing example of unit level carrying cost is the cost of money tied up in each unit of product (inventory). This cost could be out of pocket or opportunity cost. All out of pocket unit related carrying costs should be included in \$CC for the computation of ESQ. The total of these costs per year also should be added to the allocable set-up cost for allocation to each product based on the number of set-ups.

Constant Carrying Costs: Like the constant set-up costs, the total annual amount of these costs does not vary with the size of each set-up. Included in these costs are annual rent, depreciation of warehouse, salary of inventory manager and crews, insurance cost for warehouse, etc. These costs could be considered as facility-level and should not be included in \$CC for the calculation of ESQ. They should, however, be included in the total allocable set-up cost and be allocated to different products.

\section{NUMERICAL EXAMPLE}

The ensuing numerical example is developed based on the example presented by Brewer, Garrison, and Noreen in their Introduction to Managerial Accounting. ${ }^{8}$ For discussion and presentation of batch-level cost, these authors assumed $\$ 1,600,000$ machine set-up cost. As they stated "The machine set-ups activity cost pool, for example, was assigned $\$ 1,600,000$ in overhead cost. The company expects to complete 4,000 set-ups during the year, of which 3,000 will be for DVD units and 1,000 will be for CD units." ${ }^{9}$ They then demonstrated the allocation of this cost to two products, DVD and CD, based on the number of set-ups required by each, 3,000 and 1000 respectively.

In our view, the allocation process by itself is not a complicated issue. The difficult issue is the determination of the $\$ 1,600,000$ set-up cost and 3,000 and 1,000 numbers of annual set-ups. The calculations of these items should have been discussed in the textbook along with the allocation process. This shortcoming is observed even in more advanced managerial and cost accounting textbooks. 
To demonstrate the computation of the above figures by the application of ESQ model, the following interjections are made to the original example.

Annual Demand

SUC\$

Unit Cost (money tied up in each unit)

Interest Rate

CC \$ (includes only interest, $10 \%$ of Unit Cost)

\section{TYPE OF PRODUCTS}

$$
\text { DVD }
$$

$30,000,000$ units 100,000 units

\begin{tabular}{lll} 
& $\$ 400$ & \multicolumn{1}{c}{$\$ 400$} \\
$\$ 2,400$ & & $\$ 8,000$ \\
& $10 \%$ & $10 \%$
\end{tabular}

ESQ $=\sqrt{\frac{2 X(30,000,000 \text { annual demand }) X(\$ 400 \text { set-up cost })}{(\$ 240 \text { carrying cost })}=10,000 \text { Size of each set-up }}$
For DVD

$$
\begin{aligned}
& \text { Number of Set-ups for next year }=-\begin{array}{cc}
- \\
\text { ESQ }
\end{array} \\
& \text { Annual Total Set-up Cost }=\text { (Number of Set-up) X \$SUC } \\
& =(3,000) \times(400)=\$ 1,200,000
\end{aligned}
$$

Annual Total Carrying Cost $=($ Average Number of units in each set-up) $\mathrm{X}(\$ C C)$

$$
=\frac{10,000}{2} \text { - } 240=\$ 1,200,000
$$
achieved:

Applying the same procedure to the data related to the CD product, the following results would be

\author{
ESQ for $\mathrm{CD}=1,000$ units \\ Number of Set-up for next year $=\underline{\mathbf{1 , 0 0 0}}$ times \\ Annual Total Set-up Cost $=\$ 400,000$ \\ Annual Total Carrying Cost $=\$ 400,000$
}

Total Annual Set-up Cost for both DVD \& CD $=\$ 1,200,000+\$ 400,000=\$ \mathbf{1 , 6 0 0 , 0 0 0}$.

The above-calculated total annual set-up cost $(\$ 1,600,000)$ and number of set-ups $(3,000$ for DVD and 1,000 for $\mathrm{CD})$ are the same numbers that the authors of the textbook $\underline{\text { assumed }}$ in their presentation.

\title{
ALLOCABLE SET-UP COSTS
}

The major part of the allocable set-up costs in the above example is the total annual batch level set-up costs $(\$ 1,600,000)$ that were calculated in this paper but were assumed by the authors of the textbook. In addition the above costs, the total annual out of pocket unit related carrying cost also should be included in the allocable set-up costs. As mentioned before, some of the set-up and carrying costs are constant and are not included in the calculation of ESQ. These costs, however, should be included in the total allocable set-up cost and be allocated to the products based on the number of set-ups used for each product.

Assume in the above example that the constant set-up costs and carrying costs that were not included in \$SUC and \$CC for the calculation of ESQ consisted of the following items: 
Constant set-up costs:

Annual depreciation of tools used for set-up Salary of foreman supervising the set-up task

Total Constant Set-up Costs

Constant carrying costs:

Annual depreciation of warehouse

Annual salary of inventory man

Total Constant Carrying Cost for company as whole

*Assuming 10\% relates to products DVD and CD
$\$ 100,000$

$\$ 350,000$

$\$ \mathbf{\$ 5 0 , 0 0 0}$

$\$ 50,000$

$\$ 150,000$

$\$ 200,000^{*}$

$\$ 20,000$

The above constant set-up and carrying costs along with the out of pocket unit carrying costs should be added to the previously calculated total annual set-up cost of $\$ 1,600,000$. The total of these costs makes up the total annual allocable set-up costs that should be allocated to the two products based on the number of set-ups illustrated below. The authors of the managerial textbook probably have included these constant costs in General Factory cost and allocated them to products on the basis of machine hours or another basis. ${ }^{10}$

Total Allocable Set-up Costs $=$ Annual Total Set-up Costs + Total Constant Set-up Costs + Total Out of Pocket Unit Carrying Costs + Total Constant Carrying Costs

Total Allocable Set-up Cost $=1,600,000+450,000+(1,200,000+400,000)+20,000$

$$
=\$ 3,670,000
$$

Allocation of cost based on the number of set-ups:

DVD Allocable Set-up Costs $=\$ 3,670,000 \times 1000 / 40000=\$ 917,500$

CD Allocable Set-up Costs $=\$ 3,670,000 \times 3000 / 40000=\$ 2,752,500$

\section{SUMMARY AND CONCLUSION}

Most managerial and cost accounting textbooks discuss the Activity-Based Costing and classify costs into unit-level, product-level, batch-level, and facility-level costs. The example generally given by these books for the batch-level cost is the set-up cost. For demonstration purpose, these textbooks first assume some arbitrary figures for the total annual set-up cost, the number of annual set-ups and then show the allocation process. We believe it would be more appropriate if the textbooks discuss the computation of total annual set-up costs along with the allocation process. For the computation of the optimal total set-up costs, first the various factors influencing these costs should be discussed and then the methods of the allocation be applied. This paper discusses the various factors affecting the calculation of annual set-up costs. It also demonstrates a model that computes the optimum size of each set-up and the economical number of annual set-ups. Based on the outcomes of the model, the paper demonstrates the calculation of total allocable set-up cost and its allocation to various products.

\footnotetext{
${ }^{1}$ Douglas T. Hicks, “Activity-Based Costing, Making It Work For Small And Mid-Sized Companies, $2^{\text {nd }}$ Ed. (Wily), p. 4

${ }^{2}$ Robin Cooper \& Robert S. Kaplan, The Design of Cost Management Systems, $2^{\text {nd }}$ Ed (Prentice Hall), p. 210

${ }^{3}$ Robin Cooper, Robert S. Kaplan, Lawrence S. Maisel, Eileen Morrissey, and Ronald M. Oehm, Implementing Activity-Based Cost Management, (Irwin). P 13

${ }^{4}$ Kinney, Prather-Kineey, and Raiborn, "Cost Accounting, Foundation \& Evaluation”, 6e", (Thompson), p163.

${ }^{5}$ Brewer,Garisson, and Noreen, "Introduction to Managerial Accounting, 4th. Ed".(McGraw-Hill), p124

${ }^{6}$ Ibid, Kinney, Prather-Kineey, and Raiborn, p163

${ }^{7}$ Ibid, p 164

${ }^{8}$ Ibid, Brewer, Garisson, and Noreen, p 129

${ }^{9}$ Ibid, p 129

${ }^{10}$ Ibid, Brewer, Garisson, and Noreen, p 129
} 


\section{NOTES}

